\title{
What Teaching Methods Can Be Used by piano Teachers to Improve Learning Outcomes of Child and Adult Beginners?
}

\author{
Shiran $\mathrm{Du}^{1, *}$ \\ ${ }^{1}$ Faculty of Humanities and Social Sciences, St Lucia The University of Queensland Brisbane QLD 4072 Australia
${ }^{*}$ Corresponding author. Email: syrondu@gmail.com
}

ABSTRACT

The study has performed an investigation of the teaching methods that can be employed by piano teachers to improve the learning outcomes of children and adult beginners through a detailed literature review and method analysis. There are issues related to the motivation of young and adult beginners that cause challenges for them to continue their learning and practice and develop appropriate skills. Therefore, there is a need for teachers to develop an understanding of the motivation of the students based on their particular backgrounds and implement solutions to bring improvements.

The study has also investigated Alfred, Bastien, Faber and Faber, and Hal Leonard's piano methods and their suitability for beginning students. The results have shown that these methods are appropriate for piano beginners because they can provide teachers with the ability to employ demonstration skills, teaching aids, and the introduction of new theories and learning materials for indulging students in the learning process.

Keywords: Piano teaching methods, motivation, teaching aids, learning materials

\section{INTRODUCTION}

During the process of studies and teaching, I come to realize that there is a substantial gap between the traditional teaching methods followed by authoritative instructors and teaching materials and the expectations of the individuals in contemporary society. Moreover, it is rather difficult for teachers to employ various teaching methods for piano learners of different ages and cultural backgrounds considering that the teachers are not familiar with the learning motivation and habits of diverse students. For beginners, they are also confronted with huge obstacles when they desire to learn piano and continue practicing but are unable to acquire the appropriate and corresponding level of skills. Therefore, it is necessary to understand and analyze the teaching methods chosen by piano teachers to enhance the acquired technical skills and the learning outcomes of students. Similarly, some training approaches should be suggested for beginners so that they can learn independently and effectively. The research thus intends to explore the valuable and impressive piano teaching activities by combining a comprehensive review of the literature and personal experiences of learning and teaching piano. It also aims to investigate and provide musical training approaches for beginners in different age groups.

\section{LITERATURE REVIEW}

\subsection{Motivations of piano beginners}

The engagement, enjoyment, and learning of music such as piano are considered to be not only integral parts of human traits and rights, but also a source of enjoyment for learners if done in an effective way. However, while many people are engaged in learning piano, they lack the apparent motivation to attain the desired results. In this perspective, it is crucial for piano instructors to determine the level of students' motivations and adapt teaching practices and strategies accordingly in order to enhance teaching outcomes [1].

\subsubsection{Learning motivations of young piano beginners}

It has been found that while teachers utilize the same kind of strategies and behaviors in their lessons, they 
have different impacts on students. Some lose the motivation to continue the learning process or do not experience an appropriate level of pleasure and motivation to continue learning musical instruments [2]. Costa-Giomi (2004) has investigated the learning motivation of 67 th grade children engaging in a piano project. The analysis revealed that various students consider piano learning uninteresting to them and due to the lack of intrinsic motivation, they primarily indulge in the learning process because of the insistence of their parents or other external driving forces[3].

However, teachers can play a positive role in improving the piano learning motivation of young students by incorporating their preferences and choices, adjusting practicing intensity and persistence, enhancing the level of engagement, and improving tangible outputs[1]. Moreover, children's learning motivation can also be enhanced when their psychological requirements for competence, autonomy, and relatedness are satisfied [3].

Therefore, the use of effective teaching strategies and methods is essential for inspire piano beginners' intrinsic motives, thereby ultimate learning achievement [1][4][5]. It is also critical for teachers to encourage children and concentrate on their substantial improvements during the process of teaching and learning [1][6]. For example, the time duration of each lesson should be appropriately planned based upon students' attention paid to the learning activities as piano beginners may find it challenging to be continuously indulged in formal teaching for half an hour without suitable breaks. Accordingly, smaller lessons can ensure that students' learning motivation and efficiency can be consumedly incremented. Moreover, it is also recommended that opportunities be provided by the parents or guardians of young piano learners to participate in the learning process as they are better able to understand the capacity and capabilities of the children, so they can provide valuable insights in this regard.

\subsubsection{Learning motivations of adult piano beginners}

The research on piano learning has found that students in age groups of 25 to 50 are the emerging piano learners and piano is usually the preferred option for adult learners who are interested in musical instruments [7][8]. However, it has also been highlighted that if adult learners are unable to achieve a sufficient degree of competence in learning an instrument during a certain period of time, they will quickly become frustrated [9]. Therefore, it is important to understand the motivation behind adult piano beginners so that suitable teaching practices can be adopted to improve their learning experience and meet their requirements[10]. In this regard, an important consideration is that a particular teaching method may not be appropriate for all adult learners students and it is necessary for all qualified piano teachers to tailor their teaching methods and employ practices according to individual requirements.

It needs to be acknowledged that students' learning styles vary due to diverse experiences in their prior learning, the stage of life, and psychological factors [11][12]. For adult learners, the individual autonomy is considered to be of paramount significance in the learning process as compared to their young counterparts who are mainly motivated by parental verbal or nonverbal support, they prefer self-motivated and self-directed modes of learning [11][12]. Primarily, adult learners may be influenced by individual goals, activities, and learning-related reasons [12]. In this regard, the internal pleasures, suitable acquisition, and productive periodic achievement can exert a positive impact on indulging adults in continuous learning [7][13]. Further, musical self-efficacy can also function an effective role in affecting the personal choices of the learners and their relevant learning motivation[14].

Considering the above, personal pleasure, proper confidence, and a sense of accomplishment lead adult piano beginners to start their piano classes with enthusiasm. It is recommended that qualified piano teachers plan personalized lessons based on the flexible learning schedule and make efforts to encourage effective practicing. Therefore, there needs to be a focus on providing individuals with an opportunity to learn the proper piano playing technique which represents an indispensable part in the self-practicing process.

\subsection{Piano teaching methods}

\subsubsection{Alfred piano method}

This method is appropriate for students aged 7 and above which entails a variety of teaching contents, such as performing techniques, an explicit and keen understanding of the music, and theory-based learning. More importantly, this method is distinguished by its emphasis on creativity as the theoretical learning is conducted around diverse innovative activities involving music puzzles, games, students' original composition of music clips, and the acquisition of historical development of certain concepts and worldclass musicians [15][16]. Although this method does not emphasize the importance of listening and aural familiarity [20], it is significantly useful for students in younger age groups because it concentrates on the concept of position playing and applies different types of colorful graphics and pictures to improve the understanding and the overall learning experiences of the students [15]. 
Alfred's All-in-One Piano Course is designed for child beginners, which includes five books providing diverse definitions of musical terms highlighted in a pink box located at the upper left corner (see Figure 1). Moreover, there is a clapping exercise incorporating some musical symbols of rhythm located at the upper right corner and these new symbols have been applied in the following music piece. Some pages have duet parts which can be accomplished through the collaboration between teachers and students. These types of exercises will not only help students listen to the beats played by teachers and learn the method of maintaining a steady beat but they will also gain satisfaction in collective activities.

68

\section{RESTS are signs of SILENCE.}

This is a QUARTER REST.

It means REST FOR THE VALUE OF A QUARTER NOTE.

\section{Rockin' \& Rollin'}

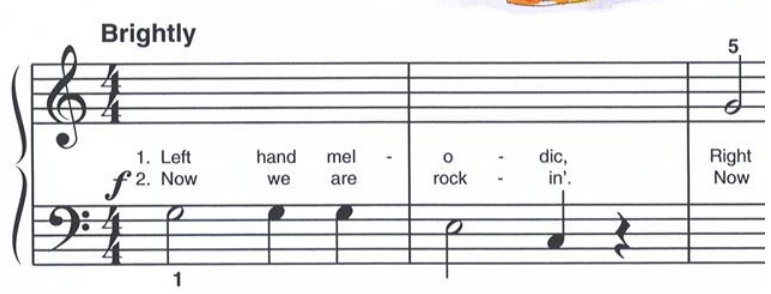

Figure 1. Alfred's Course, Book 1 Source: Alfred Music

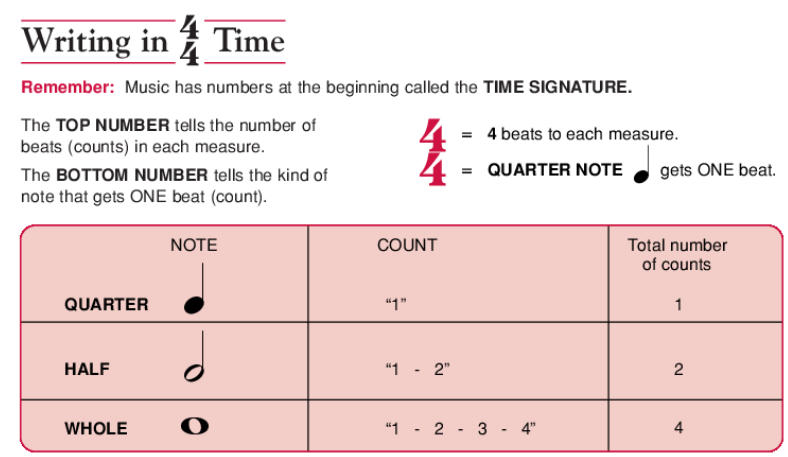

Figure 2. Alfred's Course, Book 2 Source: Alfred Music

Alfred's Course is specially designed for adult beginners which introduces a shortcutting method of acquiring musical concepts, terms, chords, intervals, progressions by appreciating the outstanding music pieces. First, considering that it has been designed for beginning adults, there are separate sections dedicated to explain the musical terms by combining both texts and graphics so that learners can get a penetrating understanding of the concepts. Besides, the book also provides practice-based learning which can enhance the internalization of the concepts in the practice of music scores.

\subsubsection{Bastien piano method}

The method concentrates on providing explanations for different types of fundamental musical theories and the ways in which piano beginners can be involved in the practicing and performing process [17]. It mainly includes five different teaching approaches involving technique, piano, performance, theory, and supplemental books which are regarded to be valuable for learners in the age group of 7 and above[16]. The beginners can not only gain a comprehensive insight into the fundamental techniques, theories, and supplemental practices but also they are equipped with abundant opportunities to understand basic dynamics, counting, and phrases[17].

The books contain attractive artworks pieces and the corresponding written assignments for enhancing students' voluntary application of the new concepts. Apart from the instruction of the theories and techniques, these musical masterpieces can be utilized by students to perform solo folk songs or functions as the basis for creating their original tunes.

It is also viable for the teachers to utilize some useful teaching aids such as colorful illustrations and themes for enhancing the motivations of the beginning learners, nurturing their suitable learning habits, and developing their technical skills. Also, the practices involved in the book share similar patterns, which results in high convenience for teachers.

\subsubsection{Faber and Faber piano method}

This method contains diverse piano learning techniques suitable for students at different levels including young children and adult students at their beginning levels [16]. Moreover, abundant sight-reading practices can be located to consolidate students' acquisition of the learned concepts from the book. The focus of the method is on the instruction, reinforcement, and creative applications pertaining to the piano theories, and this should be achieved with the help of writing, sight-reading, and activities aiming at nurturing discerning ears [16]. However, for beginners aged around 3 to 4 years old, an insurmountable hurdle may be confronted reading and understand the content. Therefore, in Faber and Faber Piano book, the off-thestaff method has been suggested, as shown in figure 3 to help beginners to read notes through letter names and directional reading. 


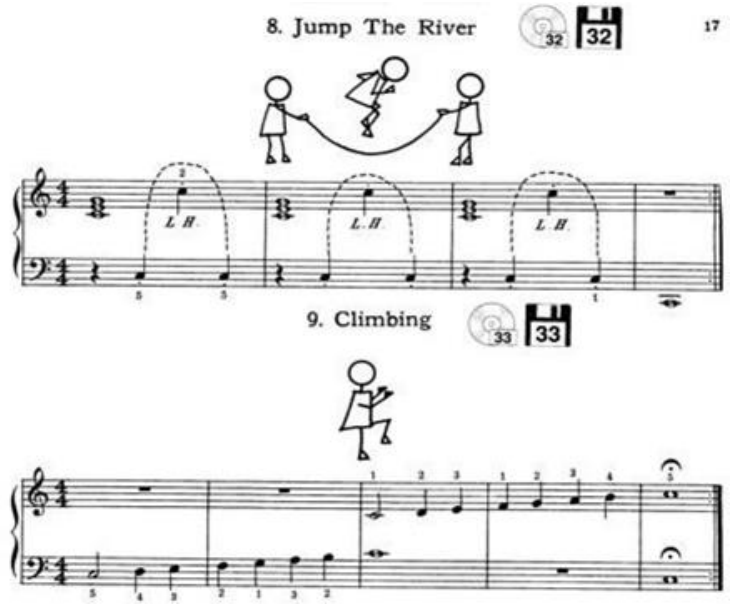

Figure 3. Pre-Reading Christmas A First Book for Piano

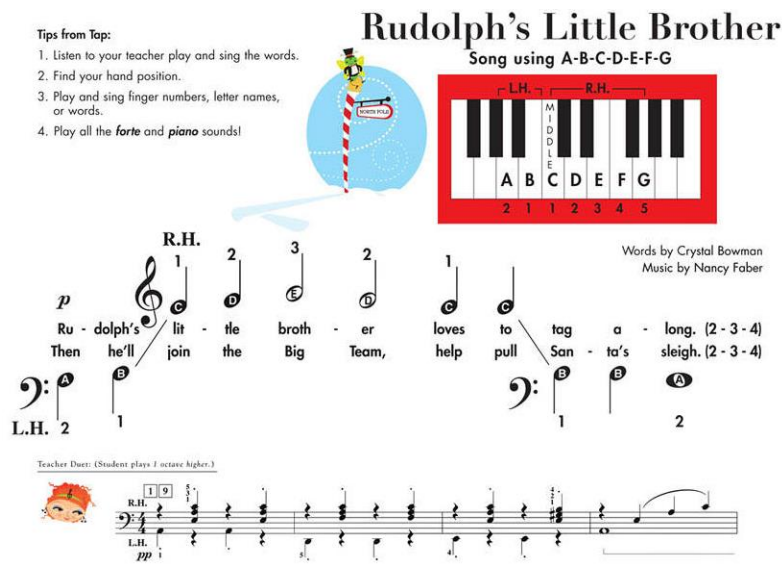

Source: FABER PIANO ADVENTURES

Figure 4. Hal Leonard A Dozen A Day - Mini Book for Piano

Meanwhile, The Faber and Faber piano method covers a relatively wide range of musical styles, such as folk songs and jazz, which can stimulate piano beginners' interest to continuously engage in the learning. In this case, these experienced teachers can make full use of effective and approachable learning methods for young, adult, and even elder piano beginners to instruct their piano learning. For example, a variety of colorful graphics and effective piano practicing suggestions, such as counting aloud provided by the book can be employed as the teaching aids to interact with piano beginners so that they can be motivated to practice correctly[16].

\subsubsection{Hal Leonard piano method}

This method introduces finger numbers with colorful illustrations and textual information that can be conveniently comprehended by the students. It is more appropriate for adult learners as it presented the sequential movements of the figures and diverse combinations of fingers during the performance, which requires a certain level of comprehension and retention. In addition, this method incorporates the fun-filled fitness plan into musical practices (see Figure 4) and these imaginary activities enable students to be immersed in the piano practicing[18][19]. It is recommended that these different types of short exercises can be conducted especially at the start of the practice session so that students can warm up their fingers and hands for formal learning. However, it is challenging for the students as they are surrounded by excessive information in the initial process of learning, which can limit their further understanding and result in students' loss of interest. In addition, it does not concentrate on listening and aural familiarity either [19][20].

\subsection{Teaching skills and musical training approaches}

\subsubsection{Demonstration skills}

When conducting music-related teaching activities, demonstration represents the primary way students acquire new skills [21]. Demonstration skills are of paramount significance for piano teachers since they provide students with the opportunity to observe the correct manner of performing different skills and techniques so that they can develop their own understanding [21]. Teachers, on the other hand, can be allowed to communicate with the students and thus positively affect their desired learning outcomes [22]. There are different types of demonstration employed in the piano class, the most common of which are recitals of musical phrases with an emphasis on critical features and movements that teachers want beginners to acquire [21]. Therefore, through effective demonstration, teachers can enhance interaction in the teaching, thereby promoting students' understanding of postures and grasping characteristics and improving their learning efficiency.

In the process of demonstration, piano teachers need to introduce new theories and learning materials progressively to ensure piano beginners can understand effectively. Based on my learning and teaching experiences, piano teachers can begin by playing a piece of music to attract beginners' attention. Following that, they might demonstrate patiently which enables novices to follow their movements and practice key signatures of a new piece of music accordingly. In the process, teachers should indulge students to focus on only one small and logical section of the musical piece at one time as this will greatly enhance the overall quality of learning. Finally, after practicing that scale numerous times in various tempos and meters, beginners will be able to string the units together using their present abilities.

Besides introducing and demonstrating new piano pieces, piano teachers should avoid exposing beginners to highly complicated and complex skills. Instead, they 
are required to choose and demonstrate pieces of piano music that are suitable for students' current level. Simultaneously, the teacher must guarantee that the newly acquired skills of piano beginners can be practiced and demonstrated repeatedly, fluently, and consistently before being taught a new one. In this way, the learned skills will be strengthened and consolidated, and valuable learning outcomes will be achieved.

\subsubsection{Teaching aids}

Over time, substantial development has taken place in teaching materials, methods, and techniques due to which it is also crucial for the teachers to combine traditional methods with new practices for improving the attention span and motivation of the learners [23]. Nevertheless, teachers may be challenged and bewildered in dealing with those who have different types of motivations and learning styles. Therefore, it is necessary for teachers to gain a penetrating insight into the individual choices, preferences, and motivation of the students, formulate personalized treatment, and apply relevant practices to improve learning outcomes.

The classical piano lessons emphasize developing students' proficient reading skills since learning of concepts has been regarded essential in the traditional teaching methods at the beginning level [24]. However, these methods do not involve an appropriate proportion of ear training, which largely consists of on-the-fly improvisation and chord practicing[25]. Hence, piano teachers can employ different types of engaging and interesting activities in the teaching practice such as games or a combination of visual and auditory activities. In this regard, diverse requirements of students from different backgrounds can be appropriately met through the involvement of ear practice, body motion, sight, touch, and cognition [23].

Piano teachers can start classes with interesting warm-up activities which are designed and organized before the formal practicing as they can enable students to prevent harmful injuries, recall the repetitive muscle memory, and enhance ear training in a harmonious manner [26]. Specifically, piano teachers stretch students' fingers, wrists, hands, shoulders, and arms by allowing them to wear finger puppets and move them with the rhymes, thereby loosening beginners' muscles and attracting their attention [27]. Furthermore, teachers can also ask students to sing along to a familiar song while playing a tune on a piano and recognizing intervals on the keys [26]. In the process, it is important for piano teachers to cover both descending and ascending scales [26].

After the effective warm-up, teachers can use their demonstration skills and proper teaching aids to stimulate students' enthusiasm. The following are some useful teaching aids for piano teachers.
The large printable music keyboard is an effective teaching aid for young piano beginners, especially children as it allows piano teachers to design and organize piano games on the floor, which makes the entire piano teaching and learning engaging and stimulating [28]. In this case, teachers can interact with piano beginners and involve them to explore the positive and entertaining side of learning an instrument, which can motivate them to continue learning piano in the long term.

The magnetic board can also be employed effectively and flexibly by piano teachers on beginners having the capability to read music (My piano teacher, n.d.). By using this method, piano novices can acquire and practice intervals without having to shuffle or select adequate materials. Compared with the traditional notecards, the flexible magnetic board enables piano beginners to move notes up or down on the stave to learn intervals (My piano teacher, n.d.).

When dealing with young piano beginners, piano teachers can combine pieces of piano music with holidays by using piano-themed holiday cards as an effective teaching aid [29]. For example, the pianothemed Halloween card can be utilized to immerse students in various Halloween music and games while the piano-themed Christmas card can also present other Christmas-related entertaining activities. Moreover, piano teachers can also provide new learners with some gifts or other rewarding incentives to encourage them to create piano-themed holiday cards [29].

The application of the Scales Plus provides piano teachers with an innovative way to teach scales to both young and adult novices since it fully uses and improves piano learners' visual and aural memories to help them study piano with high efficiency (My piano teacher, n.d). The Scales Plus equips students with a visual keyboard demonstrating the right fingering positions and revealing the corresponding notes (My piano teacher, n.d), which helps beginners to remember and understand these scales easily and efficiently. Meanwhile, the Scales Plus uses a strong color scheme on the visual keyboard inspiring students' imagination and improving their memory; however, they are only available for sale in Hong Kong (My piano teacher, n.d).

\section{CONCLUSION}

Teachers should develop an appropriate level of understanding of the motivations of piano beginners so that they can improve their teaching practices and incorporate advanced and engaging strategies that are relevant to piano learning. Based on the current study, young beginners are more intrinsically motivated and can foster continuous learning when their psychological requirements of competence, autonomy, and relatedness 
are appropriately met in the teaching practice. However, it has also been highlighted that young learners are mainly driven by external pressure and lack the appropriate level of intrinsic motivation. In this regard, the piano teachers can consider cooperating with children's parents for enhancing children's involvement and motivation. Adult learners, on the other hand, place greater emphasis on the need for personal development and skill improvement. Therefore, it is necessary for piano teachers to build on the enthusiasm of beginners and make efforts to encourage them to continue practicing skills for improvements.

The strategic piano methods originated from Alfred, Bastien, Faber and Faber, and Hal Leonard are suitable for piano beginners and this can be used in conjunction with the suggested piano training approaches, such as demonstration skills and teaching aids for enhancing students' learning outcomes in the beginning process. The teachers can introduce new theories and learning materials gradually to ensure that the beginners can fully and progressively grasp the knowledge. After all, they need to acknowledge that the difficulty of the taught skills should be appropriately suitable to the prior learning experiences and the current level of the students since extremely higher levels of complex learning contents may exert undesirable impacts on the novices. Large printable music keyboard, magnetic board, piano-themed holiday cards, and the Scales Plus are effective teaching aids to assist piano teachers to enable piano beginners to learn and practice effectively.

\section{REFERENCES}

[1] Cheng, Z., \& Southcott, J. (2016). Improving students' intrinsic motivation in piano learning: Expert teacher voices. Australian Journal of Music Education, 50(2), 48-57.

[2] Pitts, S. E., Davidson, J. W., \& McPherson, G. E. (2000). Models of success and failure in instrumental learning: Case studies of young players in the first 20 months of learning. Bulletin of the Council for Research in Music Education, 146, 51-69.

[3] Costa-Giomi, E. (2004). " I do not want to study piano!" Early predictors of student dropout behavior. Bulletin of the Council for Research in Music Education, 161/162, 57-64.

[4] Hallam, S. (2002). Musical motivation: Towards a model synthesising the research. Music Education Research, 4(2), 225-244.

[5] McPherson, G. E. (2005). From child to musician: Skill development during the beginning stages of learning an instrument. Psychology of Music, 33(1), 5-35.
[6] Creech, A., \& Hallam, S. (2011). Learning a musical instrument: The influence of interpersonal interaction on outcomes for school-aged pupils. Psychology of Music, 39(1), 102-122.

[7] Cooper, T. L. (2001). Adults' perceptions of piano study: Achievements and experiences. Journal of Research in Music Education, 49, 156-168.

[8] Jutras, P. J. (2006). The benefits of adult piano study as self-reported by selected adult piano students. Journal of Research in Music Education, 54(2), 97-110.

[9] Adamyan, A. (2018). Music Education Issues for Adult Beginners in Armenia: Specifically the Analysis of the Difficulties of Piano Playing. British Journal of Music Education, volume,1-12.

[10] Flowers, P. J., \& Murphy, J. W. (2001). Talking about music: Interviews with older adults about their music education, preferences, activities, and reflections. Update: Applications of Research in Music Education, 20, 26-32.

[11] Merriam, S. B., Caffarella, R. S., \& Baumgartner, L. S. (2007). Learning in adulthood: A comprehensive guide (3rd ed.). San Francisco, CA: John Wiley \& Sons. My piano teacher, (n.d)., Recommended Learning Aids and Materials, Retrieved from: https://mypianoteacher.net/resources/recommended -learning-aids-and-materials.

[12] Roulston, K., Jutras, P., \& Kim, S. J. (2015). Adult perspectives of learning musical instruments. International Journal of Music Education, 33(3), 325-335.

[13] Cavitt, M. E. (2005). Factors influencing participation in community bands. Journal of Band Research, 41, 42-57.

[14] Hall, K. K. (2001). Adults and computer-assistedinstruction in beginning piano: Influences on musical self-efficacy and music education attitudes. Missouri Journal of Research in Music Education, $38,4-29$.

[15] Alexander, D., Kowalchyk, G., Lancaster, E. L., McArthur, V., \& Mier, M. (2005).Alfred's Premier Piano Course Level 1A. Van Nuys, CA: Alfred.

[16] Van Sickle, K., Traut, Donald G., Cooper, Shelley, \& Pomeroy, Boyd. (2011). Assessing Five Piano Theory Methods Using NASM Suggested Theory Guidelines for Students, ProQuest Dissertations and Theses.

[17] Burns, E. (2011). The contributions of Jane Smisor Bastien to piano teaching. ProQuest Dissertations The University of Oklahoma. 
[18] Ballard, J. A. (2007). An analysis of the music content in ten piano methods (1994-2006) for the elementary-aged beginning piano student for MENC National Standards based elements. University of Southern California.

[19] Chen, Y. C. (2013). A comparison of "the music tree", "piano adventures", and "hal leonard student library" for beginning piano teachers, Retrieved from https://search-proquestcom.ezproxy.library.uq.edu.au/docview/139957490 0 ?accountid $=14723$

[20] Frewen, K. G. (2010). Effects of familiarity with a melody prior to instruction on children's piano performance accuracy. Journal of Research in Music Education, 57(4), 320-333.

[21] Simones, L., Rodger, M., \& Schroeder, F. (2017). Seeing how it sounds: Observation, imitation, and improved learning in piano playing. Cognition and Instruction, 35(2), 125-140.

[22] Zhukov, K. (2004). Teaching styles and student behaviour in instrumental music lessons in Australian conservatoriums. Sydney, Australia: University of New South Wales.

[23] Egilmez, H. O. (2012). Teaching activities directed towards the beginning stage in piano education: Visualizing, dramatizing, associating with Life. Faculty of Education Journal, 41(2), 67-75.

[24] Hayase, T. (2006). A Comparison of Akira Miyoshi's Miyoshi Piano Method with Nancy and Randall Faber's Piano Adventures Based on Royal American Conservatory Examination (Race). Doctoral dissertation, University of Cincinnati.

[25] Engel, A., Bangert, M., Horbank, D., Hijmans, B. S., Wilkens, K., Keller, P. E., \& Keysers, C. (2012). Learning piano melodies in visuo-motor or audiomotor training conditions and the neural correlates of their cross-modal transfer. NeuroImage, 63(2), 966-978.

[26] Suzy S., (2016), 5 New (and Fun) Piano Practice Warm-Up Routines, Retrieved from: https://takelessons.com/blog/piano-practice-warmups-z06

[27] Trevor, (2011), 15 Ways to Make Your Piano Lessons Wonderfully Different This Week, Retrieved from: https://www.teachpianotoday.com/2011/10/22/15ways-to-make-your-piano-lessons-wonderfullydifferent-this-week/

[28] Paradis S., (2018a), Large Printable Music Keyboard, Retrieved from: https://susanparadis.com/large-printable-musickeyboard/

[29] Paradis, S., (2018b), Piano-Themed Halloween Card, Retrieved from: https://susanparadis.com/cute-piano-halloweencard/ 